\title{
Gross' Perelmanian Sense of Rhetoric
}

Bill Morris

Kent State University

Kent, Ohio

Poroi 10,2 (December 2014)

This article focuses on how Alan Gross has treated Perelman and Olbrects-Tyteca's The New Rhetoric. I draw upon his articles on intersubjectivity (Gross, 1983), particular and universal audiences (Gross, 1999), and disassociation (Gross, 2000). ${ }^{1}$ My reading of Gross's scholarship synthesizes his thought and shows how he offers a novel Perelmanian framework.

Several features persist in Gross's Perelmanian rhetorical theory. For Gross, audience is a primary concern for rhetorical theory. In the beginning of his intersubjectivity article Gross notes that an "absolutist view of scientific truth has been generally superseded by a sophisticated and all-pervasive relativism in which truth depends not on conformity to a substratum of reality, but on intersubjective agreement among significant persons" (Gross, 1983, 69), a claim that is built on claims about the centrality of audience. This review surveys a Perelmanian sense of rhetorical audience as generative of the work of rhetors.

Building on this intersubjectivity, he claims two decades later that "at this point in our intellectual history it would be futile to argue that either philosophy or science is value-free" (Gross, 1999, 207). Gross acknowledges fluidity in the function of values in various discourses and how values relate to or establish access to the truth about reality. Gross is keen to point-out that philosophy and science are no longer activities considered separate from being value laden; they are not wholly objectively oriented activities. Grasping the Perelmanian framework Gross has in mind is a bulwark against claims that science or philosophy is not rhetorical. While this special issue is built on Gross's claims that science is rhetorical, this review traces this perspective to Perelmanian roots.

${ }^{1}$ I do not incorporate any of Gross's work on presence (Gross 2009, 2005, et.al.), since it is covered elsewhere in this special issue. 


\section{Intersubjectivity and Audience as the Core Concepts in a Perelmanian Rhetorical Theory}

In his article "Analogy and Intersubjectivity: Political Oratory, Scholarly Argument, and Scientific Reports," Gross points to the idea that "political oratory need not appeal to intellect [but that] intersubjective agreement which it seeks [...] can be reached almost entirely through the emotional use of analogy" (Gross 1983, 39). At a distance from appealing to the universal audience, Gross says that pathetic appeals in political speech still work because of intersubjective agreement. Intersubjective agreement moves closer to appeals that are aimed at convincing a universal audience because, as Gross argues, apt analogies can move toward universal appeal "depend[ing] upon the analogy's "embodiment of basic human motivations" which gives it a universal appeal on which the speaker can rely" (Gross, 1983, 39). Here, Gross surely has in mind Perelman's universal audience as the arbiter of what counts as a universal appeal.

The primary focus of "Analogy and Intersubjectivity" is to argue and demonstrate that intersubjective agreement, or individual minds aligning along a set of shared beliefs and actions, is a rhetorical mode of knowledge production distinct from foundational epistemological theories of knowledge. And, producing scholarly or scientific knowledge is "rhetorical only by analogy" to the ways in which political oratory is rhetorical (Gross 1983,45 ) if only because all three communicative acts partake in the use of analogy as productive means to reach the universal audience. The major difference among the three modes of communication is that all three have an increased access to the universal audience through their uses of appeals, with Gross demonstrating political rhetoric as having the least and scientific having the greatest access. This does not mean that political discourse does not submit claims to a universal audience, as I suggested above; it's simply a discourse with an intersubjective agreement that hews closer to emotions and values.

For Gross, some forms of discourse have increased or decreased access to appeals that seek to adhere minds to the standards of the universal audience. In 1999, Gross reflected on Perelman's notion of audience and theorized how speakers construct the audience to be, at times, particular while at other moments of a discourse the speaker projects claims for an universal audience. In the article, "A Theory of Rhetorical Audience: Reflections on Chaïm Perelman,” Gross acknowledges the controversy surrounding the application and the theoretical consistency of the universal audience, but he 
asserts that the concept of the universal audience is "part of a theoretically coherent concept of audience with considerable potential as a tool for rhetorical criticism" (Gross, 1999, 203). The theoretical coherency of Perelman's idea of audience stems from Gross's claim that audience is "a synthetic unity [that] must be a consequence of the speaker's intuition" where "speakers must embody their best guesses of their audiences' view of the two components" of what is and what ought or could be (Gross, 1999, 204). Thus Gross reads Perelman's theory so that claims of fact, truth, or presumption orient towards the universal audience and claims of value are directed at particular audiences. Again, it is worth stressing that this thematization occurs, one imagines, during the course of inventing, arranging, stylizing, memorizing and delivering an address as a consequence of the intuitive capacity of the speaker.

In this article, the sense that claims have motion is not exactly Gross's meaning. Instead, he theorizes that speaker's claims are "thematized" in ways that make them directed toward a universal audience, if, thematically, claims direct the audience towards facts, truth or presumptions. On the other hand, claims that are thematically bound to values are claims directed toward particular audiences. Much as in his article on intersubjectivity, Gross's interpretation of a rhetorical audience in light of Perelman's theory makes the kinds of address distinct from one another to tease out a sense of what might characterize a discourse as oriented toward either universal or particular audiences and concludes that "public address represents a mixture of goals, and therefore of rhetorical audiences" (Gross, 1999, 210). Thus Gross shows that speakers' intuitions characterize discourses and create a "synthetic unity," a best guess to thematize claims for both universal and particular audiences. Presumably successfully thematized claims fit the occasion and meet the exigencies of the public address.

In addition to pointing to a speaker's intuition that thematizes, Gross details how Perelman's theory of audience is clearer if we hold that there is a distinction between the real and the preferable, which also must be part of that intuition that thematizes. Gross aligns this distinction with Perelman's insight that convincing is to be distinct from persuading so that one is convinced of the real while that the preferable entails a matter of value (e.g. one could prefer to think "I am not," but, alas, making the claim that one is not one affirms that one still is). While particular audiences are urged that this or that value ought to be the case (i.e. a preference), the universal audience is convinced this or that is or is not the case. To put the point of being convinced and being persuaded to rest, 
Gross suggests that "discourse that emphasizes, that thematizes, values can never address a universal audience because particular values can never be plausibly asserted as binding on all human beings in all circumstances" (Gross, 1999, 207). What this means in part is that a speaker makes a good guess at what the synthetic whole is that the audience will prefer and know as real. This entails that the universal audience consists of those who are convinced by how a speaker's intuition and best guesses fit with what is.

Taken together, these two articles demonstrate how Gross interprets Perelman's ideas so that audiences are comprised by the speaker's intuition of disparate individuals. To become an incarnation of the universal audience an audience must share a kind of agreement, must have followed a theme where the real is distinguishable from the preferable, where values are different from facts, truths, or presumptions, and must become more or less universal at times within political discourse. That ability to share something, to follow thematizations of the real from the preferable, and to become more or less universal at times is the ability to be reasonable. By reading Gross's scholarship on Perelman in this way, one method for ascertaining the reasonableness of claims measures them against their thematization of values, facts, as best as the critic can grasp the ability of the speaker to intuit and project a synthetic unity of audience persuaded and convinced.

\section{The Realm of Rhetoric in a Perelmanian Rhetorical Theory}

Gross's "Rhetoric as a Technique and a Mode of Truth" works to memorialize one of Perelman's first American commentators by taking up an issue Henry Johnstone had had with Perelman's text. To establish that the aims of The New Rhetoric has truth in its sights, Johnstone asks a perennial question that is still a live issue among rhetoricians and philosophers, namely, whether rhetoric is a technique or a mode of truth. While Gross wisely does not answer Johnstone's question directly because much of the history of Western Philosophy is tangled up in this issue, I believe Gross's answer constitutes a "yes." Under the best conditions rhetoric is a mode of truth and the movement of disassociation helps propel discourses like philosophy and science beyond the realm of particular values into the sphere of universality where rational beings consider truth.

The purpose of "Rhetoric as a Technique and a Mode of Truth" is to highlight how disassociation is employed in various discourses ranging from political addresses to philosophical and scientific 
treatises. Gross demonstrates how political, philosophical and scientific discourses employ disassociation. Notably, philosophical and scientific discourses use disassociation along with other rhetorical devices to secure a grasp on the truth or reality of what is at issue within each discourse. As Gross interprets Perelman, philosophical discourses use disassociation and attendant rhetorical devices to separate the work of one philosopher or philosophic school from those that have been established before or those that may come in the future. For examples, Gross reads seminal philosophical texts that have as their foci questions about claims that method arrives at truth and thus at knowledge. He demonstrates that Plato and Descartes both use disassociation to separate their ideas from competing theories of how and what we can know.

Gross extends Perelman's work on disassociation within scientific discourse to claim by analogy that the scientific method is "one [device] in a class of means by which science discovers its truths" (Gross, 2000, 331). In other words, the scientific method is, in part, marked by moves we can classify as disassociative, thereby marking scientific discourses as, in part, rhetorical.

\section{Conclusion}

Gross' reading of Perelman provides a useful framework for rhetorical criticism. Gross's scholarship provides a usable method for rethinking particular and universal audiences for rhetorical criticism. His work also provides an articulation of the role of association and disassociation by demonstrating that a wide range of discourses function rhetorically. Gross's reading of Perelman also provides important infrastructure for understanding his larger project.

\section{Reference List}

Gross, A. G. "Analogy and Intersubjectivity: Political Oratory, Scholarly Argument and Scientific Reports." Quarterly Journal of Speech 69 (1983): 37-46. doi:10.1080/00335638309383633

-"A Theory of the Rhetorical Audience: Reflections on Chaïm Perelman." Quarterly Journal of Speech 85 (1999): 203-211. doi:10.1080/00335639909384254 
------ "Rhetoric as a Technique and a Mode of Truth: Reflections on Chaïm Perelman." Philosophy \& Rhetoric 33 (2000): 319335. Retrieved from http://www.jstor.org/stable/40238072

-------"Presence as Argument in the Public Sphere." Rhetoric Society Quarterly 35 (2005): 5-21. Retrieved from http://www.jstor.org/stable/40232461.

------"Presence as a Consequence of Verbal-Visual Interaction: A Theoretical Approach." Rhetoric Review 28 (2009): 265-284. doi:10.1080/07350190902958792

Gross, A. and R. D. Dearnin. Chaïm Perelman. Albany: State University of New York Press, 2003.

Jørgensen, C. "Interpreting Perelman's Universal Audience: Gross versus Crosswhite." Argumentation 23 (2009): 11-19. 